\title{
Erratum to: Implications of incomplete networks on estimation of landscape genetic connectivity
}

Ilona R. Naujokaitis-Lewis • Yessica Rico •

John Lovell · Marie-Josée Fortin · Melanie A. Murphy

Published online: 4 December 2012

(C) Springer Science+Business Media Dordrecht 2012

\section{Erratum to: Conserv Genet}

DOI 10.1007/s10592-012-0385-3

Unfortunately, in the original publication of the article, the authors inadvertently missed to acknowledge David Pilliod and Andrew Storfer for their contributions to the original dataset.

The online version of the original article can be found under doi:10.1007/s10592-012-0385-3.

I. R. Naujokaitis-Lewis $(\square) \cdot$ M.-J. Fortin

Department of Ecology and Evolutionary Biology,

University of Toronto, 25 Willcocks Street, Toronto,

ON M5S 3B2, Canada

e-mail: ilona.naujokaitis.lewis@utoronto.ca

Y. Rico

Department of Ecology and Evolutionary Biology,

University of Toronto, 3359 Mississauga Road, Mississauga,

ON L5L 1C6, Canada

J. Lovell

Graduate Degree Program in Ecology, Colorado State

University, Fort Collins, CO 80523-1177, USA

M. A. Murphy

Ecosystem Science and Management, University of Wyoming,

1000 E University Ave., Laramie, WY 82071, USA 